\title{
Substrate-treated water: a method to enhance fish activity in laboratory experiments
}

\author{
Denis Meuthen, Sebastian A. Baldauf, Theo C. M. Bakker, Timo Thünken* \\ Institute for Evolutionary Biology and Ecology, University of Bonn, An der Immenburg 1, 53121 Bonn, Germany
}

\begin{abstract}
Fast acclimatisation of experimental animals to laboratory test conditions is crucial for effective research. During highly standardized experiments, confounding parameters must be minimized which might lead to animals behaving unnaturally. The objective of the present study was to develop a simple method to enhance activity of fishes under laboratory test conditions. Many fishes intensively interact with substrate in their natural environment; however, providing substrate during experiments might impair observation or may otherwise confound the results. Therefore, the behaviour of the cichlid Pelvicachromis taeniatus was examined in water that was exposed to substrate only prior to the experiment. As a control, fish behaviour in tap water was investigated. Fish activity (i.e. covered distance) was evaluated during a period of $2 \mathrm{~h}$. In substrate-treated water fish were significantly more active than in tap water. Furthermore, males in the substrate-treated water increased their activity over time, whereas males in tap water did not. In contrast, activity of females did not change significantly over time. No significant relationship between fish activity and body size or condition was found. Furthermore, standard chemical water parameters were not altered by the substrate treatment. Thus, substrate is suggested as a means to improve the olfactory environment, promoting fish welfare and activity. In conclusion, this method is suggested as a standard with wide applicability across benthic fish species to improve acclimatisation of fishes to experimental conditions in the laboratory.
\end{abstract}

KEY WORDS: Pelvicachromis taeniatus $\cdot$ Odour $\cdot$ Sand $\cdot$ Cichlid $\cdot$ Activity patterns

\section{INTRODUCTION}

Chemical cues have been shown to play an important role in the life of fishes. Olfaction is, e.g., involved in homing (Atema et al. 2002, Gerlach et al. 2007, Dixson et al. 2008), food finding (Bardach et al. 1967, Kasumyan 2002, Barata et al. 2009), species recognition (Ojanguren \& Brana 1999, Wong et al. 2005, GuevaraFiore et al. 2010), kin recognition (Thünken et al. 2009, Mehlis et al. 2010) and predator recognition (Brown et al. 2000, Mikheev et al. 2006, Fincel et al. 2010). In cichlids, odours play a role in species recognition (Plenderleith et al. 2005) and in the recognition of parents and offspring (Nelissen 1991, Wisenden \& Dye 2009), mates (Reebs 1994), kin (Thünken et al. 2009, 2011) and predators (Foam et al. 2005), indicating that they have a well-developed olfactory sensory system. Similar to many benthic fishes, cichlids frequently interact with the substrate in their aquatic habitat (Barlow 2000). By their digging behaviour, they influence the distribution of sand across patches in rivers and lakes (Statzner et al. 2003). Also, they often transfer sand outside the nest during courtship and breeding; this behaviour might serve as a signal in conspecific interaction or as an anti-predator defence (Ochi \& Yanagisawa 1999). Extreme forms of such non-bodily signals are the sand craters built by several species of East African cichlids like Cyathopharynx furcifer (Schaedelin \& Taborsky 2010).

Therefore, cichlid welfare is positively influenced by access to substrate (Galhardo et al. 2008), and cichlids prefer sandy over other environments (Galhardo et al. 2009).

However, under experimental conditions, the presence of substrate might be disadvantageous. In experiments, fish then often show a lack of contrast when observed from above, which makes the evaluation of their behaviour difficult (e.g. by analyzing video-recordings). Additionally, the digging behaviour of cichlids (Ochi \& Yanagisawa 1999, Statzner et al. 2003) might impair ob- 
servation. Hence, a natural setting during experiments has to be carefully traded off against difficulties of observation. As a result, substrate is often removed from experimental setups at the cost that fish might behave unnaturally.

The aim of the present study was to develop a noninvasive method of increasing fish activity in a novel environment. Instead of providing sand as a substrate, water previously exposed to sand ('sand-treated water') was used in the experiment, and fish behaviour in sand-treated water was compared with that in tap water. Experiments were conducted with males and females of the cichlid Pelvicachromis taeniatus (Boulenger, 1901). It has a well-developed sense of smell and is able to discriminate between its own and familiar kin chemical cues (Thünken et al. 2009). Also, $P$. taeniatus males interact intensively with available sand and construct sand piles in front of their breeding caves (Baldauf 2006).

Fishes are known to reduce their swimming behaviour (i.e. speed or distance) in response to unfavourable or novel conditions (Godin 1997, Brown et al. 2001, Huntingford et al. 2006, Wilson et al. 2010). Therefore, the covered distance was measured as a proxy for activity and acclimatisation. Among cichlids, males are the predominant sex in substrate interaction, especially in the context of nest building (Baldauf 2006, Mendonça et al. 2010, Schaedelin \& Taborsky 2010). Thus, one would predict that male P. taeniatus show a stronger response than females to sand-treated water.

\section{MATERIALS AND METHODS}

Experimental animals. Fish were descendants of wild-caught Pelvicachromis taeniatus from the Moliwe River near Limbe, Cameroon ( $04^{\circ} 04^{\prime} \mathrm{N}, 09^{\circ} 16^{\prime}$ E). Prior to the experiment, the experimental fish were kept in mixed sex groups with up to 30 individuals in five $60 \times$ $45 \times 30 \mathrm{~cm}$ (length $\times$ width $\times$ height) tanks, equipped with java moss Taxiphyllum barbieri and sand as substrate. The tanks were positioned on a white polystyrene layer and separated from each other by opaque plastic sheets. Illumination was provided in a $12 \mathrm{~h}$ light:12 h dark cycle (from 09:00 to 21:00 h) by fluorescent tubes (Lumilux Plus Eco L36W/21-840, Osram) $8 \mathrm{~cm}$ above the tank. Water temperature was kept constant at $25 \pm 1^{\circ} \mathrm{C}$. Fish were fed daily ad libitum with a mix of defrosted food that contained mosquito larvae of the genera Chironomus, Culex and Chaoborus, as well as Artemia sp. in a ratio of 2:1:0.25:1

Water preparation. Preparation of the water used for the treatment groups was conducted in four $50 \times 30 \times$ $30 \mathrm{~cm}$ (length $\times$ width $\times$ height) tanks, called 'prepara- tion tanks' from now on. One day prior to the experiment, tanks were filled with $40.5 \mathrm{l}$ of tap water. To create sand-treated water, three $105 \mathrm{ml}$ cups filled with substrate were added to half of the preparation tanks. The substrate used in the experiment was commercially obtained Rhine sand that consists of $>90 \%$ quartz sand. The substrate consisted of approximately $5 \%$ fine sand (particles $<0.18 \mathrm{~mm}$ ), $75 \%$ of the volume was medium sand ( 0.18 to $0.50 \mathrm{~mm})$ and $10 \%$ was coarse sand $(0.50$ to $1.50 \mathrm{~mm})$. The last $10 \%$ of the total volume consisted of fine gravel $(1.50$ to $3.50 \mathrm{~mm})$. The $315 \mathrm{ml}$ volume used for each sand-water preparation tank weighed on average $( \pm \mathrm{SD}) 413.32 \pm 19.06 \mathrm{~g}(\mathrm{n}=$ 10). Sand in the holding tanks was of the same origin as that used in the experiments. The tanks used for preparing sand-treated water and tap water were cleaned after conducting all experiments each day. Subsequently, treatments were reassigned to the tanks randomly; a sand-water tank was always placed next to a tap-water preparation tank.

Experimental design. The experiments were conducted in four $30 \times 20 \times 20 \mathrm{~cm}$ tanks placed in a square fashion. Each tank was covered with a $30 \times 20 \mathrm{~cm}$ transparent, $1 \mathrm{~cm}$ thick Plexiglas pane.

Furthermore, all tanks were surrounded by a white polystyrene layer to prevent visual contact between fish. This setup was placed on a $74 \mathrm{~cm}$ high table. Tanks were illuminated by a fluorescent tube (Lumilux Plus Eco L36W/21-840, Osram) placed $70 \mathrm{~cm}$ above the tanks. For video recording, a web camera (QuickCam Pro 9000, Logitech) was placed $57 \mathrm{~cm}$ above the experimental setup.

Experimental procedure. Each day, the tanks were filled with $9 \mathrm{l}$ of the previously prepared water in such a way that diagonally positioned tanks became the same treatment. Prior to filling the experimental tanks, the temperature of the prepared water was adjusted to $25.0^{\circ} \mathrm{C}$. Prepared water came from the same preparation tank only once per day.

Fish holding tank origin was randomized such that fish of the same sex and from the same holding tank did not meet the same conditions (water type, preparation tank, experimental tank). Four experimental fish were carefully captured with a hand net and put into a $15.5 \times 9 \times 11 \mathrm{~cm}$ transportation box each filled with $1 \mathrm{l}$ of tap water. Each fish was then, alternately for the 2 treatments, introduced into its experimental tank. Subsequently, the behaviour of all 4 fish was recorded for $2 \mathrm{~h}$. Per treatment group 6 males and 6 females were tested. Each fish was only used once, resulting in 24 experiments.

Body measurements and behavioural analysis. Subsequent to each experiment, fish standard length (SL: body size from snout to the beginning of the tail fin) was measured to the nearest millimetre, and body 
mass $(M)$ was determined (LC 221S, Sartorius). The body condition factor ( $C F$ ) was calculated after Bolger \& Connolly (1989) such that:

$$
C F=100 \times M \times\left(\mathrm{SL}^{3}\right)^{-1}
$$

Recordings of the experiments were analyzed by tracking the fish with the software BioObserve. Track length was used as an operational variable to infer activity. For every fish, the total track length covered in $2 \mathrm{~h}$ was calculated. In order to analyze activity changes during the experiment, track length was also computed in $1 \mathrm{~min}$ intervals over the duration of the experiment.

Water analysis. Furthermore, chemical water parameters were obtained from 6 different instances of either treatment. The $\mathrm{pH}$ and electrical conductivity (EC) values were obtained with a digital meter (HI 98129, Hanna Instruments, measurement errors: $\mathrm{pH}$ 0.05 units, EC $2 \%)$. Alkanity (carbonate hardness) $\left(\mathrm{kH}_{1}\right.$ measurement error $0.009 \mathrm{mmol} \mathrm{l}^{-1}$ ), total or general hardness $\left(\mathrm{gH}\right.$, measurement error $\left.0.004 \mathrm{mmol} \mathrm{l}^{-1}\right)$, nitrate $\left(\mathrm{NO}_{3}^{-}\right.$, measurement error $\left.2.5 \mathrm{mg} \mathrm{l}^{-1}\right)$, nitrite $\left(\mathrm{NO}_{2}^{-}\right.$, measurement error $\left.0.005 \mathrm{mg} \mathrm{l}^{-1}\right)$ and ammoniac $\left(\mathrm{NH}_{3} / \mathrm{NH}_{4}{ }^{+}\right.$, measurement error $\left.0.025 \mathrm{mg} \mathrm{l}^{-1}\right)$ values were identified using drip tests (JBL). Also, the amount of diluted oxygen $\left(\mathrm{O}_{2}\right)$ was obtained twice in a $45 \mathrm{~min}$ interval per water analysis using an oxygen probe (OxiCal-SL, WTW, measurement error 0.5\%) connected to a digital meter (OxiCal 842, WTW). The values of both oxygen measurements were averaged for statistical analysis. Carbon dioxide saturation $\left(\mathrm{CO}_{2}\right)$ was calculated based on the $\mathrm{pH}$ and $\mathrm{kH}$ values using the formula:

$$
\mathrm{CO}_{2}\left(\mathrm{mg} \mathrm{l}^{-1}\right)=\mathrm{kH}\left(\mathrm{mmol} \mathrm{l}^{-1}\right) \times 44 \times 10^{(\mathrm{pK}-\mathrm{pH})}
$$

with a calculated mean pK of 6.321 by incorporating temperature and EC according to Norm DIN 38404-10 (1995).

Statistical analyses. All statistics were computed using the R 2.5.1 statistical package. In order to examine whether the treatment (i.e. tap water or sandtreated water) influenced fish activity, linear models (LM) were conducted. Tests of statistical significance were based on likelihood ratios (LRT). Hence, degrees of freedom always differed by 1 . Non-significant factors and interactions were removed from the analysis (Engqvist 2005). The total track length the test fish covered was entered as a dependent variable, and 'treatment' and 'sex', as fixed factors. Furthermore, the interaction between 'treatment' and 'sex' was included in order to test whether males and females responded differently to the treatment. For analyzing activity changes over time, for each of the 24 experiments Spearman rank correlation tests between track length per minute and time were conducted. The correlation coefficients obtained were entered in a LM as the dependent variable, and 'treatment' and 'sex', as fixed factors. To examine sex-specific differences, the interaction between 'treatment' and 'sex' was included. Parametric tests were applied only when the data were normally distributed according to the Shapiro-Wilk test. When data were not normally distributed, nonparametric tests were applied. Test probabilities are 2-tailed throughout.

\section{RESULTS}

The mean $( \pm \mathrm{SD})$ total track length covered by Pelvicachromis taeniatus in the sand-treated water group was almost twice as high as that in the control group (LRT, $F=4.991$, df $=1, \mathrm{p}=0.036$; Fig. 1). This difference was independent of sex (interaction sex $\times$ treatment, LRT, $F=1.032$, df $=1, \mathrm{p}=0.332$ ). Also, the sexes did not cover significantly different total distances (LRT, $F=0.207, \mathrm{df}=1, \mathrm{p}=0.654$ ). Activity changes over experimental time were significantly explained by the interaction between treatment and sex (LRT, $F=4.595$, $\mathrm{df}=1, \mathrm{p}=0.045$; Fig. 2). Female activity did not significantly change over time in either treatment (tap water: LM, intercept, $t=1.476$, df $=5, \mathrm{p}=0.200$; sand-treated water: LM, intercept, $t=1.518, \mathrm{df}=5, \mathrm{p}=0.189$; Fig. 2), nor did male activity in tap water (LM, intercept, $t=$ 1.485, df = 5, p=0.198; Fig. 2). However, males significantly increased their activity over time in sandtreated water (LM, intercept, $t=5.805, \mathrm{df}=5, \mathrm{p}=0.002$; Fig. 2). Body measures did not differ significantly

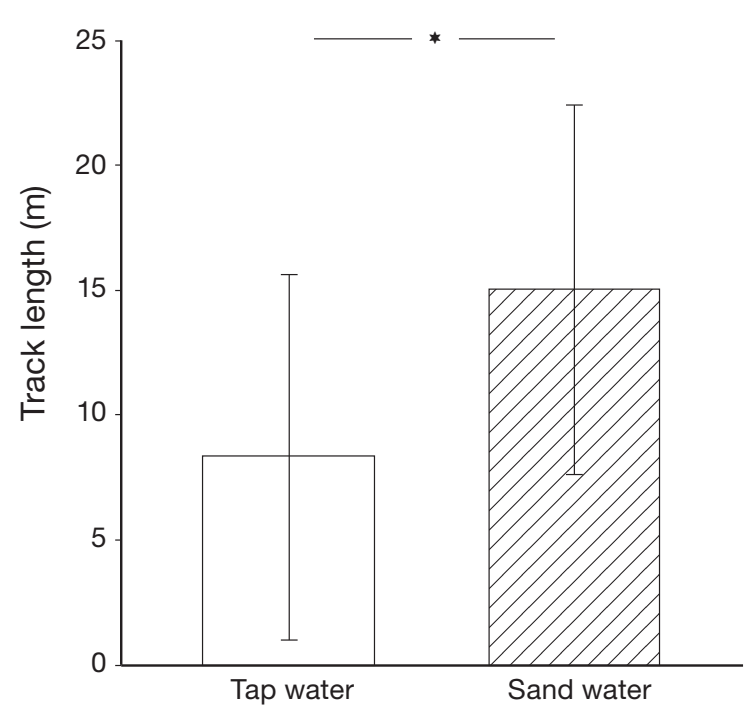

Fig. 1. Pelvicachromis taeniatus. Mean $( \pm \mathrm{SD})$ total track length the fish covered during $2 \mathrm{~h}$ in tap water (white) and sand-treated water (hatched). The asterisk above the bars indicates $\mathrm{p}<0.05$ 


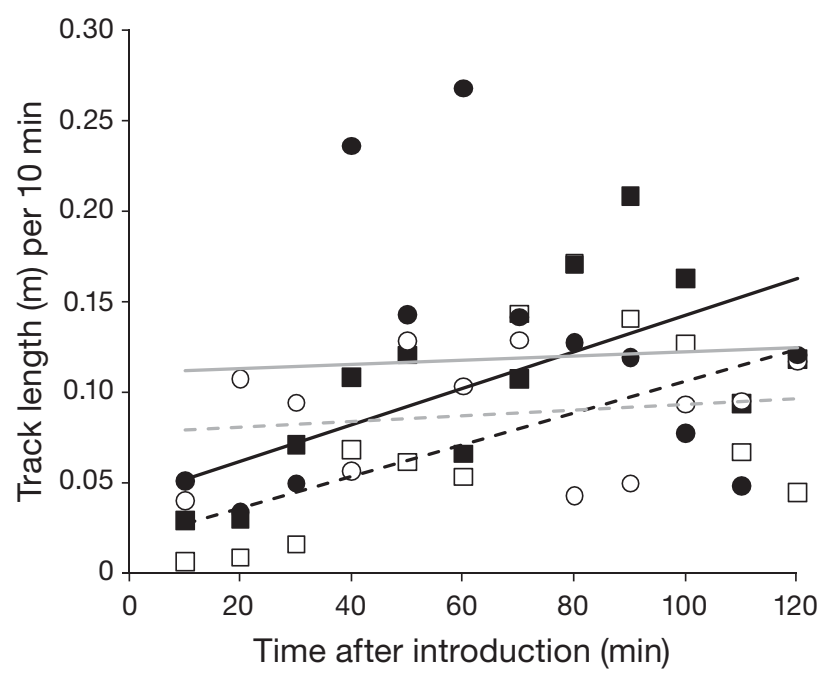

Fig. 2. Pelvicachromis taeniatus. Track length per successive 10 min intervals by males (squares, black regression lines) and females (circles, grey regression lines) in tap water (open symbols, dashed regression lines) and sand-treated water (filled symbols, solid regression lines) during the $2 \mathrm{~h}$ experiment

between the fish in the sand-treated water and control treatments (standard length: mean \pm SD: $4.91 \pm 0.86$ vs. $4.96 \pm 0.92 \mathrm{~cm}$, independent Wilcoxon test, $W=75.5$, $\mathrm{p}=0.862$; body mass: mean \pm SD: $3.01 \pm 1.21$ vs. $3.16 \pm$ $1.43 \mathrm{~g}$, independent Wilcoxon test, $W=74, \mathrm{p}=0.932$; condition factor: mean \pm SD: $2.51 \pm 0.43$ vs. $2.50 \pm 0.43$, independent $t$-test, $t=-0.035, \mathrm{df}=22, \mathrm{p}=0.973$ ). Also, activity (i.e. total track length) was not significantly correlated with standard length (Spearman rank correlation, $\mathrm{r}=-0.203, \mathrm{n}=24, \mathrm{p}=0.341$ ), body mass (Spearman rank correlation, $\mathrm{r}=-0.123, \mathrm{n}=24, \mathrm{p}=0.564)$, or condition factor (Pearson correlation, $\mathrm{r}=0.083, \mathrm{n}=24$, $\mathrm{p}=0.471)$. The physical water parameters were not significantly different between treatments (Table 1).

Table 1. Comparison of water parameters from sand-treated water $(n=6)$ and tap water $(\mathrm{n}=6)$. Shown are means $( \pm \mathrm{SD})$, test statistics and p-values. Nitrite $\left(\mathrm{NO}_{2}^{-}\right)$ and ammoniac $\left(\mathrm{NH}_{3} / \mathrm{NH}_{4}{ }^{+}\right)$concentrations were below measurement thresholds in all cases, and thus, statistics could not be performed. The nitrate $\left(\mathrm{NO}_{3}{ }^{-}\right)$values were identical in each measurement and, thus, were not statistically analyzed. $\mathrm{kH}$ : carbonate hardness; $\mathrm{gH}$ : general hardness

\begin{tabular}{|c|c|c|c|c|}
\hline Parameter & Tap water & $\begin{array}{c}\text { Substrate-treated } \\
\text { water }\end{array}$ & $\begin{array}{c}\text { Test } \\
\text { statistic }\end{array}$ & $\mathrm{p}$-value \\
\hline $\mathrm{pH}$ & $8.37 \pm 0.05$ & $8.36 \pm 0.07$ & $W=18$ & $>0.999$ \\
\hline Conductivity $(\mu \mathrm{S})$ & $369.17 \pm 25.31$ & $370.16 \pm 25.47$ & $t=0.068$ & 0.947 \\
\hline $\mathrm{kH}\left(\mathrm{mmol} \mathrm{l}^{-1}\right)$ & $1.53 \pm 0.19$ & $1.59 \pm 0.26$ & $t=0.452$ & 0.662 \\
\hline $\mathrm{gH}\left(\mathrm{mmol} \mathrm{l}^{-1}\right)$ & $1.03 \pm 0.12$ & $1.03 \pm 0.12$ & $W=11$ & $>0.999$ \\
\hline $\mathrm{NO}_{3}^{-}\left(\mathrm{mg} \mathrm{l}^{-1}\right)$ & $5 \pm 0$ & $5 \pm 0$ & - & - \\
\hline $\mathrm{NO}_{2}^{-}\left(\mathrm{mg} \mathrm{l}^{-1}\right)$ & $<0.01$ & $<0.01$ & - & - \\
\hline $\mathrm{NH}_{3} / \mathrm{NH}_{4}^{+}\left(\mathrm{mg} \mathrm{l}^{-1}\right)$ & $<0.05$ & $<0.05$ & - & - \\
\hline $\mathrm{O}_{2}\left(\mathrm{mg} \mathrm{l}^{-1}\right)$ & $8.34 \pm 0.33$ & $8.20 \pm 0.26$ & $t=-0.791$ & 0.448 \\
\hline $\mathrm{CO}_{2}\left(\mathrm{mg} \mathrm{l}^{-1}\right)$ & $0.65 \pm 0.22$ & $0.60 \pm 0.10$ & $W=18.5$ & $>0.999$ \\
\hline
\end{tabular}

\section{DISCUSSION}

Generally, the activity of Pelvicachromis taeniatus was positively influenced by substrate-induced alteration of tap water. Fish were significantly more active in sand-treated water than in tap water independent of sex. Variation in body size, mass, or condition did not significantly correlate with activity, which contrasts to some other studies (Budaev et al. 1999, Reebs 2002). Significant differences between the sexes were found in activity changes over time. Males started with a somewhat lower activity than females, especially compared to females in sand-treated water. The males in the sand-treated water significantly increased their activity over time, whereas those in the control group did not. In the case of females, neither group developed significantly higher activity over time. The different responses of the sexes may be not surprising, because substrate is a resource more relevant for $P$. taeniatus males, which construct sand piles in front of their breeding caves (Baldauf 2006). Also, recent research has determined that in other cichlid species predominantly males use substrate for nest building (Mendonça et al. 2010, Schaedelin \& Taborsky 2010). Sexes may also differ in learning ability and thereby in activity (Sneddon 2003). Another explanation is that males might be the choosier sex in P. taeniatus (Baldauf et al. 2009) and thus be more cautious.

Substrate treatment did not alter any measured chemical water parameters significantly. Also, microorganisms could not be detected in water samples, whereas microscopically small pieces of organic particles were present in higher quantity after substrate treatment (D.M., personal microscopic observations, magnification 400x). The results suggest that the difference in activity is not due to an effect of substrate on waterquality parameters (Broom \& Johnson 1993), but rather implies that fish recognized the chemical trace of the substrate. Furthermore, it is likely that this odour is mediated through microscopically small organic particles. In other experiments, different authors found increased fish activity in tanks containing substrate (Webster \& Hart 2004, Galhardo et al. 2009). Thus, recognition of substrate odours in the water might similarly influence fish welfare positively even without actual substrate interaction. Since the same type of substrate was available in the holding tanks, one may assume that the substrate odours represented a familiar environment (Gerlach et al. 2007).

The present research showed that activity of the cichlid Pelvicachromis 
taeniatus was positively influenced by using water that had been pre-treated with sand. Providing olfactory enrichment by using this simple method may be widely applicable in the study of different fish species that inhabit sandy habitats in order to facilitate acclimatization to minimalistic experimental setups.

Acknowledgements. The authors thank the Bakker research group for discussion of the manuscript. This research was funded by the Deutsche Forschungsgemeinschaft (DFG) (BA 2885/2-3).

\section{LITERATURE CITED}

Atema J, Kingsford MJ, Gerlach G (2002) Larval reef fish could use odour for detection, retention and orientation to reefs. Mar Ecol Prog Ser 241:151-160

Baldauf SA (2006) Der Einfluss von Verwandtschaft auf Partnerwahl und Brutpflegeverhalten bei Pelvicachromis taeniatus (Cichlidae). MSc thesis, University of Bonn, Bonn

Baldauf SA, Kullmann H, Schroth SH, Thünken T, Bakker TCM (2009) You can't always get what you want: size assortative mating by mutual mate choice as a resolution of sexual conflict. BMC Evol Biol 9:129

Bardach JE, Todd JH, Crickmer R (1967) Orientation by taste in fish of the genus Ictalurus. Science 155:1276-1278

Barata EN, Hubert F, Conceicao LEC, Velez Z, Rema P, Hubbard PC, Canario AVM (2009) Prey odour enhances swimming activity and feed intake in the Senegalese sole. Aquaculture 293:100-107

Barlow GW (2000) The cichlid fishes: nature's grand experiment in evolution. Perseus Publishing, Cambridge, MA

Bolger T, Connolly PL (1989) The selection of suitable indexes for the measurement and analysis of fish condition. J Fish Biol 34:171-182

Broom DM, Johnson KG (1993) Stress and animal welfare. Chapman \& Hall, London

> Brown GE, Paige JA, Godin JGJ (2000) Chemically mediated predator inspection behaviour in the absence of predator visual cues by a characin fish. Anim Behav 60:315-321

> Brown GE, Adrian JC, Patton T, Chivers DP (2001) Fathead minnows learn to recognize predator odour when exposed to concentrations of artificial alarm pheromone below their behavioural-response threshold. Can J Zool 79: 2239-2245

Budaev SV, Zworykin DD, Mochek AD (1999) Consistency of individual differences in behaviour of the lion-headed cichlid, Steatocranus casuarius. Behav Processes 48:49-55

Dixson DL, Jones GP, Munday PL, Planes S and others (2008) Coral reef fish smell leaves to find island homes. Proc Biol Sci 275:2831-2839

Engqvist L (2005) The mistreatment of covariate interaction terms in linear model analyses of behavioural and evolutionary ecology studies. Anim Behav 70:967-971

- Fincel MJ, Chipps SR, Voldseth RA (2010) Chemically-mediated predator inspection behavior by fathead minnow (Pimephales promelas). J Freshwat Ecol 25:279-283

Foam PE, Mirza RS, Chivers DP, Brown GE (2005) Juvenile convict cichlids (Archocentrus nigrofasciatus) allocate foraging and antipredator behaviour in response to temporal variation in predation risk. Behaviour 142:129-144

Galhardo L, Correia J, Oliveira RF (2008) The effect of substrate availability on behavioural and physiological indica- tors of welfare in the African cichlid (Oreochromis mossambicus). Anim Welf 17:239-254

Galhardo L, Almeida O, Oliveira RF (2009) Preference for the presence of substrate in male cichlid fish: effects of social dominance and context. Appl Anim Behav Sci 120: $224-230$

Gerlach G, Atema J, Kingsford MJ, Black KP, Miller-Sims V (2007) Smelling home can prevent dispersal of reef fish larvae. Proc Natl Acad Sci USA 104:858-863

Godin JGJ (1997) Evading predators. In: Godin JGJ (ed) Behavioural ecology of teleost fishes. Oxford University Press, Oxford

Guevara-Fiore P, Stapley J, Krause J, Ramnarine IW, Watt PJ (2010) Male mate-searching strategies and female cues: How do male guppies find receptive females? Anim Behav 79:1191-1197

> Huntingford FA, Adams C, Braithwaite VA, Kadri S, Pottinger TG, Sandoe P, Turnbull JF (2006) Current issues in fish welfare. J Fish Biol 68:332-372

Kasumyan AO (2002) Sturgeon food searching behaviour evoked by chemical stimuli: a reliable sensory mechanism. J Appl Ichthyology 18:685-690

> Mehlis M, Bakker TCM, Engqvist L, Frommen JG (2010) To eat or not to eat: egg-based assessment of paternity triggers fine-tuned decisions about filial cannibalism. Proc Biol Sci 277:2627-2635

Mendonça FZ, Volpato GL, Costa-Ferreira RS, Gonçalves-deFreitas E (2010) Substratum choice for nesting in male Nile tilapia Oreochromis mossambicus. J Fish Biol 77: 1439-1445

Mikheev VN, Wanzenbock J, Pasternak AF (2006) Effects of predator-induced visual and olfactory cues on $0+$ perch (Perca fluviatilis L.) foraging behaviour. Ecol Freshwat Fish 15:111-117

Nelissen MHJ (1991) Communication. In: Keenleyside MHA (ed) Cichlid fishes: behavior, ecology, and evolution. Chapman \& Hall, London

Norm DIN 38404-10 (1995) German standard methods for the examination of water, waste water and sludge-Physical and physicochemical parameters (Group C), Part 10: calcit saturation of water (C 10). Beuth Verlag, Berlin

Ochi H, Yanagisawa Y (1999) Sand-transfer behavior outside the nest by guarding parents of the Tanganyikan cichlid, Neolamprologus caudopunctatus. Ichthyol Res 46:419-422

> Ojanguren AF, Brana F (1999) Discrimination against water containing unrelated conspecifics and a marginal effect of relatedness on spacing behaviour and growth in juvenile brown trout, Salmo trutta L. Ethology 105:937-948

Plenderleith M, van Oosterhout C, Robinson RL, Turner GF (2005) Female preference for conspecific males based on olfactory cues in a Lake Malawi cichlid fish. Biol Lett 1: 411-414

> Reebs SG (1994) Nocturnal mate recognition and nest guarding by female convict cichlids (Pisces, Cichlidae, Cichlasoma nigrofasciatum). Ethology 96:303-312

Reebs SG (2002) Plasticity of diel and circadian activity rhythms in fishes. Rev Fish Biol Fish 12:349-371

Schaedelin FC, Taborsky M (2010) Female choice of a nonbodily ornament: an experimental study of cichlid sand craters in Cyathopharynx furcifer. Behav Ecol Sociobiol 64:1437-1447

> Sneddon LU (2003) The bold and the shy: individual differences in rainbow trout. J Fish Biol 62:971-975

> Statzner B, Sagnes P, Champagne JY, Viboud S (2003) Contribution of benthic fish to the patch dynamics of gravel and sand transport in streams. Water Resour Res 39:1309-1325 
Thünken T, Waltschyk N, Bakker TCM, Kullmann H (2009) Olfactory self-recognition in a cichlid fish. Anim Cogn 12: 717-724

Thünken T, Baldauf SA, Kullmann H, Schuld J, Hesse S, Bakker TCM (2011) Size-related inbreeding preference and competitiveness in male Pelvicachromis taeniatus (Cichlidae). Behav Ecol 22:358-362

Webster MM, Hart PJB (2004) Substrate discrimination and preference in foraging fish. Anim Behav 68:1071-1077

Wilson RS, Lefrançois C, Domenici P, Johnston IA (2010) Envi-

Editorial responsibility: Leif Asbjørn Vøllestad, Oslo, Norway ronmental influences on unsteady swimming behaviour: consequences for predator-prey and mating encounters in teleosts. In: Domenici P, Kapoor BG (eds) Fish locomotion: an eco-ethological perspective. Science Publishers, Enfield Wisenden B, Dye T (2009) Young convict cichlids use visual information to update olfactory homing cues. Behav Ecol Sociobiol 63:443-449

Wong BBM, Fisher HS, Rosenthal GG (2005) Species recognition by male swordtails via chemical cues. Behav Ecol 16: 818-822

Submitted: December 15, 2010; Accepted: April 15, 2011

Proofs received from author(s): June 23, 2011 